\title{
Effective CALD community health communication through research and collaboration: An exemplar case study
}

\author{
Jim Macnamara \\ University of Technology Sydney \\ Michael Camit \\ University of Technology Sydney
}

\begin{abstract}
Health communication is identified as an important strategy in achieving health outcomes, particularly in supporting preventative approaches to combatting disease and ill-health. In Australia's multicultural society, health communication needs to address a number of CALD communities in order to achieve health objectives and social equity. While cross-cultural and intercultural communication have been widely studied, research shows that health communication often fails to achieve its objectives, particularly in CALD communities. This analysis examines a case study that highlights three key ingredients of effective health communication targeting CALD communities - in-depth qualitative formative research, a collaborative community-based approach, and cultural competency. The case study reveals how a culture-centred approach (CDA) and social ecology model of health communication achieved results that exceeded targets by up to $100 \%$ on a relatively small budget, but also revealed gaps in cultural competency that disadvantage some groups. This study contributes to health communication theory and practice, as well as public communication generally, by providing insights into ways to increase effectiveness as well as cost-efficiency, which in turn creates scalability and sustainability.
\end{abstract}

Key words: Health communication, CALD, cross-cultural, collaboration, evaluation

\section{Health communication, health promotion, and social marketing}

Health communication has gained increasing scholarly attention since the early 1970s when the International Communication Association (ICA) established a Therapeutic Communication Interest Group in 1972 and then broadened its focus in 1975 to a renamed Health Communication Division (Kreps, 2014, p. 569). It has been a growing field of research and practice since the 1980s when a number of research and text books started appearing on the subject (e.g.., Kreps \& Thornton, 1988; Northouse \& Northouse, 1985) and the first specialist journals appeared (e.g., Health Communication in 1989).

Health communication involves a number of strategies to address health-related issues ranging from disease prevention to workplace safety (Atkin \& Silk, 2009; Parrott, 2004). The US Government's Healthy People 2010 strategy, which included a landmark commitment to health communication, defines the practice as "the art and technique of informing, influencing, and motivating individual, institutional, and public audiences about important health issues" (Department of Health and Human Services, 2000). In 2010, the US Government launched Healthy People 2020 in which one of "four over-arching goals" is to "promote quality of life, healthy development, and healthy behaviours across all life stages" (CDC, 2011; see also http://www.healthypeople.gov). The Harvard School of Public Health defines health

1 The project reported was supported by a \$100,000 Evidence to Practice grant from Cancer Institute NSW and the voluntary work of many community leaders and organisations. 
communication as "the study of how health information is generated and disseminated and how that information affects individuals, community groups, institutions and public policy" (Harvard, 2016). Kreps (2003) says that health communication is a "resource" that allows health messages (for example prevention, risk or awareness) to be used in the education and avoidance of ill health.

There are two main branches of health communication discussed in research literature. The first is focussed on health care delivery and involves mainly interpersonal and small group communication such as that occurring between doctors, nurses, emergency services (e.g., ambulance and paramedics), and patients (e.g., see Slade et al., 2015 ). This field involves study of health care teams, provider-consumer relationships, and therapeutic communication (e.g., as undertaken by psychiatrists and counsellors). The second is referred to as health promotion in health and medical disciplines and as health communication among communication and media scholars. This field is involved in the use of information and persuasive communication to promote public health (Kreps, Bonaguro, \& Query, 1998). The latter is the purpose of the project analysed here.

While Kreps et al. (1998) refer to health promotion as one of two branches of health communication, others see differences between the fields of practice. For instance, Corcoran (2007) describes health communication as enabling a "holistic approach to health promotion". In this perspective, health communication is part of health promotion - the latter also including interventions such as screening services. Australian Commonwealth Government policy seems to support this view, as its Web site lists a number of health interventions such as cancer screening services as well as public communication campaigns under 'Health promotion' (Australian Government, 2016). The world Health Organisation (WHO) also defines health promotion broadly as "the process of enabling people to increase control over their health and its determinants, and thereby improve their health" (WHO, 2005). This clearly suggests that health promotion involves more than communication. Therefore, this analysis uses the term 'health communication' as it focusses specifically on public communication activities undertaken to support public health objectives.

Some health communication programs and campaigns are conducted and described under the rubric of social marketing (Hastings \& Stead, 2006; MacFadyen, Stead, \& Hastings, 2003). The term 'social marketing', first used by Kotler and Zaltman (1971), refers to the application of commercial marketing theories and practices to attempt to reduce or resolve social problems such as ill-health. Commercial marketing and social marketing have traditionally relied heavily on mass media campaigns using advertising and publicity (Stead \& Hastings, 1997). However, studies of media effects have shown that mass media campaigns are seldom effective in changing behaviours in relation to health (e.g., Bryant \& Oliver, 2009).

It is also important to note that research indicates that social marketing campaigns in general are mostly unsuccessful in achieving their objectives. For instance, Rossiter and Bellman (2005) reported that only $10 \%$ of such campaigns are successful. This does not necessarily indicate the unsuitability of such approaches or implementation problems. As Noble and Camit (2010) note, changing addictive behaviours such as smoking is more difficult than many commercial marketing objectives such as selling a low-cost consumer product. Also, MacFadyen, Stead, and Hastings (1999) note that social marketers frequently need to address audiences within the least accessible and hardest to reach sections of society - factors particularly relevant to the project discussed here.

A problem that has beset many traditional approaches to health communication is that they have been framed within modernism and development communication theory in which they are 
based on an assumption that experts know what is best for communities. As Dutta and de Souza state, such approaches have involved a "one-way flow of communication from the centre", which has been:

... based on the assumption of expertise of those at the center, who could examine an underdeveloped community, evaluate its needs based on scientific instruments, and propose solutions that would supposedly propel the community toward development; the category of the 'underdeveloped' was fixed in its position as the object of interventions, its people portrayed as the 'primitive' receivers of campaign messages who were incapable of development without the helping hand of the interventionists. (Dutta \& de Souza, 2008, p. 327)

Contrasting top-down modernist and development communication approaches criticized by Dutta and de Souza (2008), Panter-Brick, Clarke, Lomas, Pinder, and Lindsay (2006) propose a social ecology model of health communication, which "focuses attention on the contexts of behaviour when designing, implementing or critical evaluating interventions" (p. 2810). Specifically, Panter et al. say: "We use the term social ecology to focus attention on the social and physical settings contextualising behaviour as well as the interplay between human actors and external factors shaping their agency” (2006, p. 2811).

Informing this approach is that Panter-Brick et al. note that "behaviour change is notoriously difficult to initiate and sustain" and they observe that "the reasons why efforts to promote healthy behaviours fail are coming under increasing scrutiny" (2006, p. 2810) - a further factor relevant to this study. In fact, citing a wide range of health communication literature they say "there are remarkably few examples of truly successful health interventions" (p. 2811). They recommend:

To be successful, health interventions should build on existing practices, skills and priorities, recognise the constraints on human behaviour, and either feature community mobilisation or target those most receptive to change. Furthermore, interventions should strive to be culturally compelling, not merely culturally appropriate: they must engage local communities and nestle within social and ecological landscapes. (2006, p. 2810)

As well as its obvious epidemiological and clinical focus, public health now recognises that "health is profoundly affected by the social, political, environmental, and behavioural factors with which people live" and that communication is central to achievement of public health objectives (Bernhardt, 2004, p. 2052).

More recently, Dutta and colleagues have advocated a "culture-centered approach" (CCA) to health communication that "seeks to address health disparities by fostering opportunities for listening to the voices of those at the margins through a variety of participatory communication methods", which they describe as including "co-constructive data gathering and analysis", "community dialogues", "community-driven media advocacy", and "town hall meetings" (Dutta, Anaele, \& Jones, 2013, p. 160). Dutta says that co-construction, which he describes as "a process of collaboration and power sharing between academics and marginalized communities, lies at the heart of the CCA" (Dutta et al., 2013, p. 160). These theoretical frameworks, which draw on understandings of user-centred design, co-production, and cocreation from other disciplines (e.g., Tanaka, Gaye, \& Richardson, 2010), are particularly relevant and important in planning, implementing, and evaluating health communication with culturally and linguistically diverse (CALD) communities, as will be shown. 


\section{Health communication with CALD communities}

CALD communities have been identified as groups requiring particular focus in public communication and in health communication specifically. CALD communities are often among those identified by MacFadyen, Stead, and Hastings (1999) as the least accessible and hardest to reach sections of society. While many migrants integrate into mainstream society, many others live largely within geographic and cultural enclaves and do not access services and information resources available to the wider community. For example, research has reported that there is a marked reluctance among people from culturally and linguistically diverse backgrounds to voluntarily access both hospital and community-based mental health services (McDonald \& Steel, 1997; Minas, Lambert, Kostov, \& Boranga, 1996). This particularly applies to older migrants.

As a number of studies have noted, Australia has one of the most diverse migrant populations in the world (e.g., Rao, Warburton, \& Bartlett, 2006). At 30 June 2013, 27.7\% of the estimated resident population of Australia was born overseas, amounting to 6.4 million people, and this is increasing - up from 23.6\% (4.7 million people) in 2003 (Australian Bureau of Statistics, 2013). In the Australian state of New South Wales where this case study was situated, the Ministry of Health Policy and Implementation Plan for Healthy Culturally Diverse Communities 2012-2016 recognises that "people from culturally diverse backgrounds are diverse in terms of religion, cultural values and social structures" (NSW Ministry of Health, 2012) and the state government has adopted policies supporting specialised projects and programs for CALD communities.

In addressing this topic, concern about the adequacy of the term 'CALD' is recognised (e.g., Sawrikar \& Katz, 2009). These groups are also referred to as ethnic; multicultural; communities from non-English speaking backgrounds (NESB); and by new terms such as ethnically diverse and different from the majority (EDDM) (Sawrikar \& Katz, 2009). However, the term CALD remains in common use and is used respectfully and inclusively in this analysis.

This analysis critically reviews a project to increase breast screening rates among women from Indian and Sri Lankan backgrounds in the age range of 50 to 74 living in NSW that was funded by Cancer Institute NSW and undertaken by the NSW Multicultural Health Communication Service.

Migrants from India and Sri Lanka are one of the largest and fastest growing ethnic groups in Australia, and particularly in NSW (Australian Bureau of Statistics, 2013). Immigration patterns indicate that, over the coming years, there will be a substantial increase in women aged 50 to 74 years of age in these cultural groups. This is the age range in which women are most susceptible to breast cancer (Pelissier et al., 2014). However, Cancer Institute NSW data show that women from India and Sri Lanka living in Australia have among the lowest rates of breast screening (mammograms) - the primary recommended strategy for early detection and treatment of breast cancer. In its brief for the project discussed in this analysis, Cancer Institute NSW advised:

1. In NSW, approximately one in five women of Tamil or Hindi speaking background [the two main languages spoken by Indian and Sri Lankan women living in NSW] participate in breast screening. This compares with about one in two women in the general population;

2. The vast majority of women who speak Hindi or Tamil in NSW do not regularly attend BreastScreen;

3. In NSW, Tamil speaking women are about four times less likely to participate in breast screening compared with women in the general population; 
4. In NSW, Hindi speaking women are about one third less likely to participate in breast screening compared with women in the general population;

5. Hindi and Tamil speaking women are the two culturally and linguistically diverse groups least likely to participate in breast screening in NSW.” (Cancer Institute NSW, 2014)

The health needs of older people from CALD backgrounds are likely to be "particularly acute as a result of cultural and language barriers; their geographical location and the circumstances of migration, which impact on their financial circumstances; as well as psycho-social health" (i.e., emotional, mental, and spiritual factors), according to a study by Rao, Warburton, and Bartlett (2006, p. 174). Furthermore, they note that, despite a range of government and community stakeholders involved in addressing these issues, "the evidence base for policy and practice is not well understood".

To address the context and challenges outlined - notably the fact that many health communication campaigns fail to achieve their objectives; that CALD communities are among the hardest to reach sectors in society; that there is reluctance among CALD communities to access health services; and a continuing lack of understanding of the sociocultural and sociopsychological circumstances of CALD communities - the project analysed employed the social ecology model of health communication (Panter-Brick, 2006) and a culture-centered approach (CDA) (Dutta, 2008, 2012; Dutta et al., 2013) and is analysed within those theoretical frameworks.

In addition, the design and analysis of this case study is informed by the extensive body of literature on evaluation of health communication (e.g., Bauman \& Nutbeam, 2014; Hornik, 2002; Nutbeam, 1998; Shiavo, 2014) and evaluation of public communication generally (Rice \& Atkin, 2002; Rossi, Freeman, \& Lipsey, 2004; Valente, 2001; Wholey, Hatry, \& Newcomer, 2010). Bauman and Nutbeam advocate three stages of research for evaluation - formative evaluation (pre-intervention to inform planning), process evaluation during interventions to track progress; and impact evaluation post-intervention (2014, p. 35). Valente spells out that a comprehensive evaluation framework should include assessing needs; conducting formative research to design messages; designing treatments (activities or interventions), comparisons, instruments, and monitoring methods; process research; summative research; and sharing results with stakeholders and other researchers (as cited in Rice \& Atkin, 2002, p. 428).

\section{Methodology}

This study is based on mixed method case study analysis of the Pink Sari project undertaken by the NSW Multicultural Health Communication Service (MHCS), a specialist division of the NSW Ministry of Health in 2014-2015. A descriptive case study approach was taken as defined by Yin (2009). More specifically and importantly, the project analysed represents an instrumental case study as described by Stake (1995), undertaken to gain insight into an issue or refine a theory. As Schramm said "the essence of a case study is that it tries to illuminate a decision or set of decisions: why they were taken, how they were implemented, and with what result" (1971, p. 6). This project met the definition of a case worthy of analysis and discussion based Stake's and Schramm's criteria and Johansson's summary that a case selected for study should "be a complex functioning unit, be investigated in its natural context with a multitude of methods, and be contemporary” (Johansson, 2003, p. 2).

\section{Research questions}

The overarching research question explored in this case study analysis was 'How can the challenges of and barriers to effective health communication with CALD communities be identified and overcome?' In particular, given the focus of the communication project studied 
and also the relatively modest funding available ( $\$ 100,000$ for a 12 months project), specific research questions explored were:

RQ 1: How can women from Indian and Sri Lankan backgrounds aged 50 to 74 living in NSW be persuaded to regularly undertake breast screening (mammograms)?

RQ 2: How can health communication with CALD communities be undertaken in a way that is both effective in achieving its objectives and cost-efficient?

\section{Research methods}

As advised by Johansson (2003) and others in relation to case study analysis (e.g., Miles \& Huberman, 1994; Stake, 1995; Yin, 2009), multiple research methods are applicable and several should be applied to 'triangulate' data and provide confirmability and transferability in qualitative studies, as well as reliability when quantitative analysis is undertaken. In this case, a mixed method approach was used involving quantitative and qualitative research to address the research questions. While the two 'how' RQs mainly required examination of qualitative factors, assessing the effectiveness of the project in increasing rates of breast screening required quantitative data analysis. In total, four research methods were used in analysing this case study as follows.

1. Ethnography was a primary source of information about this case as the authors were firsthand observers and participants in the project. As Geertz (1973) noted, personal observation and sometimes participation by the researcher are primary methods used in ethnography. While ethnography has some limitations - most notably the potential for the presence and subjectivity of researchers to influence findings - Geertz described ethnography as 'thick description' because it is based on detailed observation, interpretation, and sometimes participation during an extended period of field work. Creswell further draws attention to key characteristics, benefits, and methods of this method in his definition of ethnography as "a strategy of inquiry in which the researcher studies an intact cultural group in a natural setting over a prolonged period of time by collecting, primarily, observational and interview data” (2009, p. 13). The deep involvement of the researchers in this project during its 12-months duration and during the following six months undertaking evaluation (total 18 months), supported by other research methods as outlined in the following, meets the methodological requirements outlined by Geertz (1973), Creswell (2009), and others such as Tedlock (2008).

As Maréchal (2010) notes, ethnographic as well as autoethnographic research are distinguished from simple autobiographical stories and subjective accounts by (1) reflexivity and (2) the connection of observations to wider cultural, political, and social meanings and understandings - i.e., data from other sources. The researchers attempted to be conscious of power relations and their own worldview and perspective and how these might influence the research. This was addressed through the open collaborative approach employed in the project, being self-critical towards assumptions and reflective as the project progressed, and particularly by confirming and verifying observations using other data sources such as independently recorded minutes of meetings of the Project Steering Group and reports and e-mails from organisations and community leaders involved. Furthermore, the following research methods both informed and confirmed ethnographic observations.

2. Interviews were conducted with executives of MHCS, Project Steering Group members, and some community leaders. These were informally conducted in the form of discussions 
that took place over several months face-to-face, by telephone, and by e-mail. During the 12 months duration of the project, more than 20 informal interviews were conducted.

3. Content analysis of mainstream and ethnic media coverage as well as social media was undertaken. This used NVivo 10 to qualitatively analyse 47 media articles reporting or commenting on the project, 166 Facebook wall posts, tweets and retweets on Twitter, and seven videos on YouTube that attracted almost 1,000 views. These were analysed to identify issues discussed and key messages;

4. Statistical analysis of data extracted from the database of the Cancer Institute NSW was undertaken post-hoc by exporting data into Microsoft Excel tables for comparative analysis with breast screening rates in previous years for the CALD groups studied.

\section{The Pink Sari project}

Cancer Institute NSW is the state government agency responsible for reducing the incidence of cancer in the community, increasing survival rates, and improving the quality of life of cancer patients and their carers through public education, research, and other interventions. As well as conducting its own research and health promotion campaigns, the institute awards annual grants to other organisations that can demonstrate an ability to contribute to achieving its objectives. Cancer Institute NSW requires rigorous evaluation of such projects to demonstrate effectiveness and results, ideally at a behavioural change level.

In 2014, the NSW Multicultural Health Communication Services (MHCS) successfully applied for a Cancer Institute NSW grant of AUD\$100,000 to conduct a 12-month project to increase awareness and rates of breast screening of women from Indian and Sri Lankan backgrounds aged 50-74 living in NSW. The project was implemented from 1 July 2014 to 30 June 2015, with evaluation data collected up to December 2015.

\section{Objectives}

The overall goal of the project was to increase breast cancer screening rates among women from Indian and Sri Lankan backgrounds aged $50-74$ in NSW by at least 5\% from the baseline rate as per data collected by BreastScreen NSW and the Cancer Institute NSW. Other communication objectives were to:

1. Increase knowledge of enablers and barriers to address current low rates of screening among women from Indian and Sri Lankan backgrounds in NSW;

2. Increase awareness and influence positive community attitudes to breast screening; and

3. Increase the capacity of screening services to engage effectively with the target communities.

\section{Approach}

From the outset, this project employed a critical-cultural approach common to the social ecology model of health communication, which involves "reflexive interrogation of modernist assumptions underlying health communication campaigns” (Dutta \& de Souza, 2008, p. 326). To facilitate this, the approach began with extensive formative research to inform strategy and activities. To help design and undertake formative as well as evaluative research, MHCS engaged a team of academic researchers at the University of Technology Sydney (UTS). Another key element of the approach was establishment of a Project Steering Group made up of key stakeholders in line with best practice program planning and evaluation as recommended by the European Commission (2015). Members of the Project Steering Group included representatives of the NSW Refugee Health Service and BreastScreen Liverpool, a breast 
screening clinic in an area of Indian and Sri Lankan migrant concentration, as well as MHCS senior executives and two academic researchers. The Project Steering Committee also consulted with local area health services (e.g., South-West Sydney Local Health District).

Four methods of formative research were deployed as follows:

1. A global literature review of academic and professional research in relation to cancer detection programs targeting CALD communities including screening for breast and cervical cancer. This resulted in a 24-page report detailing international research findings in relation to promotion of cancer detection services that helped inform planning of the project (Macnamara, Dunston, \& Monden, 2014);

2. A survey of women in the target audience to identify their knowledge, awareness, and attitudes towards cancer, particularly breast cancer, and gain insights into their motivations and/or de-motivations in relation to breast cancer screening and their primary sources of information in relation to health. The survey was administered to a convenience sample via face-to-face intercept interviews during major gatherings of Indian and Sri Lankan women such as at events to celebrate Deepavali $(\mathrm{n}=206)$ and online using SurveyMonkey ( $\mathrm{n}=94$ ), yielding a total of 300 responses. They survey questionnaire was structured in three parts, with 20 closed-end questions to collect information about participants such as their cultural background, preferred languages, proficiency in English, preferred media channels, and health history; 18 closed-end questions on their understanding of and attitudes towards breast screening (mammograms); and six closed-end questions to collect demographic information such as age, occupation, and socio-economic status. While $\mathrm{n}=$ 300 from an estimated 7,500 women in the target audience did not provide high statistical reliability, the survey data usefully informed project planning, particularly when combined with other data;

3. Focus groups among women from Indian and Sri Lankan backgrounds in the target age range to explore and probe understandings, perceptions, attitudes, and knowledge in relation to breast cancer and breast screening. Four (4) focus groups were conducted involving 36 women from Hindi, Tamil Indian, Tamil Muslim, and Sinhalese backgrounds. Participants were recruited through a call for volunteers distributed via relevant community groups. In addition, informal discussions were held with 15 representatives of key intermediaries including Indian and Sri Lankan General Practitioners (GPs), refugee health workers, and community health professional;

4. A cultural competency study of a breast screening clinic in an area with a high Indian and Sri Lankan population to address communication objective 3 and noting that cultural competency is identified in the literature as a key requirements for engaging and delivering services to CALD communities (NHMRC, 2005; Renzaho, Romios, Crock, \& Sønderlund, 2013). An independent consultant with experience in service design for multicultural groups was appointed to undertake the cultural competency study during the first three months of the project.

\section{Formative research findings}

The global literature review conducted by the academic researchers in the first stage of the project (Macnamara, Dunston, \& Monden, 2014) revealed a number of key social and cultural issues that contributed to a 'culture of silence' among these communities in relation to breast cancer (p. 8) and that are important to planning health communication. These included: 
- A belief that breast cancer is a "white woman's disease" that it does not affect South Asian women (Bottorff et al., 1998, p. 2081; Bottoroff et al., 2001). Related to this is a belief that Western lifestyles contribute to breast cancer and that women "bring it on themselves" by having a "negative" lifestyle (Johnson et al. 1999, p. 246);

- A widespread belief that if a woman does not have symptoms, there is no need to do anything in relation to breast health. From their studies of South Asian women living in Canada, Bottoroff et al. reported that "the notion of asymptomatic screening was foreign to these women” (1998, p. 2081);

- A belief that cancer is an "illness that doesn't have a cure ... a death sentence" (Bottorff et al., 1998, p. 2080) and that there is "no point in doing anything to prevent, detect or treat breast cancer” (Bottorff et al. 1998, p. 2081);

- Concern that daughters will not be considered good marriage partners if their mother has had breast cancer (Meneses \& Yarbro, 2007, p. 108);

- The importance of honour among many cultures. Bottoroff et al. noted that "it is important to the women to protect their family honour at all costs" and going to a medical centre connected with cancer is potentially a loss of honour for the family (1998, p. 2079);

- Modesty has been found to be a key barrier for Muslim women in relation to mammography and other health care treatments (Saadi, Bond, \& Percac-Lima, 2012, p. 636), and is also very important to South Asian women (Karbani et al., 2011). Karbini et al. reported that South Asian women "expressed difficulty in communication within their family and to healthcare professionals, particularly to male doctors about health issues related to their body (i.e., 'feminine problems')" (2011, p. 1622);

- Sensitivities in relation to discussion of or treatment associated with breasts, as noted by Karbani et al. (2011, p. 1622) and Bottorff et al. (1998, p. 2080), who reported that the word 'breast' is linked to sexuality.

The survey and focus groups conducted among women from Indian and Sri Lankan backgrounds living in Sydney confirmed a number of the findings from the literature including deep-seated fears and superstitions, concern for family honour, and high levels of modesty. For example, comments in focus groups included the following.

I felt shy. I went alone and I was shy to remove the dress. I really felt very shy.

It's a fear, like daughter also has or daughter will also get it.

If we thinking like that there is no marriage right for the daughters. For the women's having cancer those daughters definitely can't get the marriage.

Some people saying if it comes let it come anyway we are going to die.

The survey also revealed a lack of knowledge about breast cancer among women from Indian and Sri Lankan backgrounds living in NSW; a lack of understanding of English and poor translations of information materials from English; and, while women of Indian and Sri Lankan backgrounds use mass media including 'ethnic' newspapers as a source of local news, they do not attach credibility to mass media as a source of information about health issues. They rely mostly on their peers, families, and local communities for health information, including local Indian and Sri Lankan doctors and community leaders.

As noted already, cultural competence (CC) has been identified in research literature as vitally important for effective delivery of services to CALD communities (NHMRC, 2005; Renzaho et al., 2013). The Australian National Health and Medical Research Council says that cultural competence "focuses on the capacity of the health system to improve health and wellbeing by 
integrating culture into the delivery of health services” (NHMRC, 2005, p. 7). In simple terms, cultural competence in the context of this study includes factors such as the level of cultural understanding among staff working in service delivery (e.g., of issues identified in research such as fears, superstitions, and modesty concerns), availability of translators, and knowledge and skills to meet the preferences and expectations of people from CALD backgrounds. The study of the cultural competency of a breast screening clinic revealed a number of deficiencies. These included a failure to consistently offer or provide translators to women with poor English in a number of instances; a failure to clearly specify that breast screening was done by women with no men present; and a general lack of knowledge of the beliefs, concerns, or preferences of women of Indian and Sri Lankan backgrounds.

\section{Strategy}

Based on formative research findings, MHCS developed a strategy incorporating:

1. Establishment of community partnerships with a wide range of organisations representing and interacting with women from Indian and Sri Lankan backgrounds. As well as members of the Project Steering Group such as the NSW Refugee Health Service and BreastScreen NSW clinics in relevant areas, partnerships were established with key stakeholders such as the Sri Lankan Health Professionals' Association, the Indian Doctor's Association, the Sri Lankan and Indian Welfare Association, Migrant Resource Centres, and women's health services in Local Health Districts. This was in line with Dutta et al.'s CCA approach in which "culturally centered projects of social change begin by building partnerships between academics and disenfranchised communities" and which calls for "processes of dialogue and listening that foreground community voices at sites of knowledge production and implementation” (2013, p. 161);

2. Identification of community champions. Through the partnerships established, a number of 'community champions' and leaders were identified and engaged in spearheading the project. While these included Indian and Sri Lankan doctors and some elected officials and religious leaders, an important feature of the project was that many community champions were everyday members of the community including some women who had survived breast cancer and were willing to support the project;

3. Based on these partnerships and their outreach into Indian and Sri Lankan communities, community-based collaborative planning and design were used to develop the project. This included collaborative design of all materials from naming of the project and logo design to planning all activities undertaken as part of the project (see 'Pink Sara Project activities');

4. All information materials were written or rewritten 'in language' by native speakers of each of the key languages including Tamil, Hindi, and Sinhalese - not as direct translations of English language content. This, and preceding initiatives, were directly informed by the advice of members of the community gained from the survey, focus groups, and interviews and are in line with the social ecology model of health communication (Panter-Brick, et al., 2006) and the culture-centred approach to health communication (Dutta, 2008; Dutta, 2012; Dutta, et al., 2013).

\section{Pink Sari Project activities and interventions}

Based on the in-depth research conducted, the community-based collaborative project implemented a range of activities in the 12 month period July 2014-June 2015. These included, in summary: 
1. Creation of the 'Pink Sari' name, logo and artwork - based largely on ideas and suggestions from the community (see Figure 1);

2. Development of a Pink Sari Project Web site (http://pinksariproject.org);

3. Creation of a Pink Sari Facebook page (https://www.facebook.com/thepinksariproject);

4. A number of Pink Sari community leaders' forums were held at which 'community champions' were briefed and engaged in the project;

5. Community information sessions were held for women from Indian and Sri Lankan backgrounds;

6. A Pink Sari pledge was created in which women were encouraged to write a pledge to have a breast screen or encourage other women to have one;

7. Women from Indian and Sri Lankan backgrounds marched in pink saris carrying BreastScreen banners in the Parramasala parade through the streets of Parramatta, Sydney. Parramasala is a major annual festival held each October involving street parades, food stalls, music, dance, poetry, film, art, and street performances;

8. A Pink Sari fashion show was held in June 2015, planned and organised by volunteers from the Sri Lanka Association of NSW;

9. A Pink Sari Photo Exhibition of 14 breast cancer survivors was held in the Blacktown Arts Centre on 27 August 2015 (planned during the project period). Indian and Sri Lankan women came up with the idea, volunteered, and 14 leading photographers from Indian or Sri Lankan backgrounds donated their time to create the exhibition that was publicly displayed for several months;

10. Another innovative initiative in the Pink Sari Project was to enlist daughters, who are mostly more educated and Westernised than older generations, to encourage their mothers to have a breast screen through online videos, pledges, and personal communication (see https://www.youtube.com/watch?v=7OcfXUDoFdo\&feature=youtu.be);

11. The various activities undertaken resulted in a large amount of highly favourable media publicity in ethnic media and some mainstream Sydney newspapers;

12. The study of the cultural competency of a BreastScreen NSW clinic made recommendations to increase cultural competency as a key enabler of increased breast screening for CALD groups through training of staff, increased access to translators, and guarantees of privacy during breast screening.

Figure 1. The Pink Sari logo that, along with all project materials, was produced in bright pink.

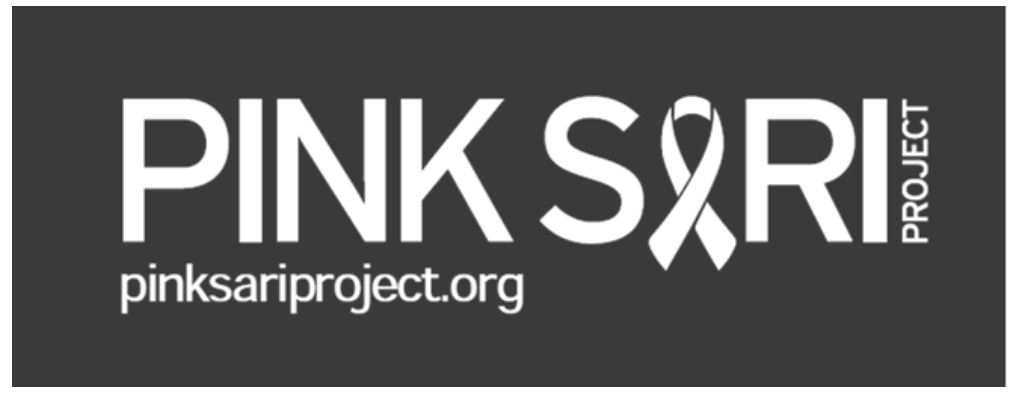

\section{Project results}

In accordance with program evaluation models and best practice in health communication as well as public communication generally, the Pink Sari Project was evaluated not only in terms of its outputs but, more importantly, its outcomes and impact in relation to the project's objectives (Bauman \& Nutbeam, 2014; Macnamara, 2015; Watson \& Noble, 2014; Wholey et al., 2010). In the interests of space, the large amount of data collected to demonstrate outputs, outcomes and impact are summarised in the following dot points and figures. 


\section{Outputs}

- 55 Pink Sari events were attended by 10,462 women from Indian or Sri Lankan backgrounds during the 12 months of the project (1 July 2014 to 30 June 2015);

- 100 Tamil doctors voluntarily engaged in outreach to Indian and Sri Lankan women in their communities to encourage breast screening;

- 100 women turned out in pink saris to participate in the Parramasala Parade through the streets of Parramatta in October 2014 and again in October 2015;

- The Pink Sari Fashion Show was a sell-out and generated positive publicity in local and ethnic media;

- 14 women from Indian and Sri Lankan backgrounds who survived breast cancer and 14 leading photographers from Indian or Sri Lankan backgrounds volunteered to produce the Pink Sari Photo Exhibition;

- Volunteer time and resources contributed to the project are estimated at \$300,000 (e.g., donation of pink saris, donation of photo exhibition space and video production, volunteer workers, free media space to promote Pink Sari events, etc.) - a 3:1 return on investment;

- The Pink Sari Facebook site gained 951 likes (fans) overall in the 12 months of the project. This is a significant number given the target audience of Indian and Sri Lankan women aged 50-74 living in NSW totals around 2,500). In addition, the Pink Sari Project Facebook site attracted 7,589 video views; 1,796 likes of 140 posts (including text, photos, and videos); 565 shares of content; and 73 comments, of which all except one were positive;

- $\quad$ Almost 1,000 video views were gained on YouTube $(n=951)$;

- While media publicity was not a primary communication channel in the project, supporting media publicity in city, local and ethnic press included 47 media articles in city and suburban media, 99.5\% of which was positive and included 252 placements of key messages that supported the objectives of the project (see Figure 2).

Figure 2. Key messages communicated in media publicity about the Pink Sari Project.

\section{KEY MESSAGES IN MEDIA PUBLICITY}

Indian and Sri Lankan women are at risk because of low rates of breast screening (risk/vulnerabilty)

Breast screening is widely recommended and supported (community norm)

Breast screens are effective in early detection and treatment of cancer (effectiveness / solution)

Women aged 50-74 should phone 132050 , go to the Pink Sari Web site, or talk to a loved one (Call to action)

General support for breast screening

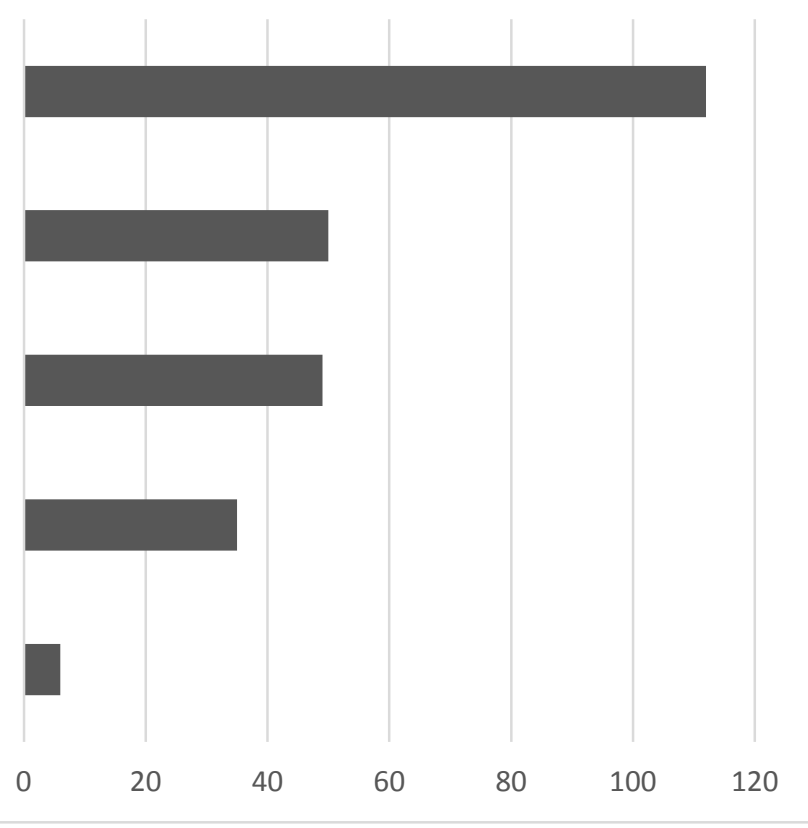

Interviews with participants during the project confirmed the high level of engagement in and support for the project. Comments included: 
I've never seen such community engagement and uptake of an idea in my career (personal communication, de-identified NSW Refugee Health Service executive, October 7, 2015);

The project is really making a difference (personal communication, de-identified multicultural health worker, Northern Sydney Local Health District, August 5, 2015).

\section{Outcomes and impact}

Most importantly, this project was evaluated in terms of outcomes and impact against objectives. Data on breast screening of women in NSW broken down by age, ethnicity, and other factors collected by Cancer Institute NSW (2015) was analysed, although this stage of quantitative analysis proved difficult for two reasons. First, when asked by BreastScreen clinics to describe their ethnicity and main language spoken, many immigrant women answer 'Australian' and 'English' even though they are from non-English speaking backgrounds. This means that data in these fields in breast screening database records are not complete. However, comments and notes recorded in the database often contain information on cultural background and language proficiency. Time-consuming analysis of unstructured data had to be undertaken using keyword searches and matched to relevant database fields to provide a more complete picture of women having mammograms. Second, Cancer Institute NSW advised that it was State Government policy to not release the numbers of women having breast screens broken down by ethnic group. However, percentage change data verified by Cancer Institute NSW are able to be released and these show that in the financial year 1 July 2014 to 30 June 2015 (the period of the Pink Sari Project), there was:

- An 8\% increase in the total number of Indian and Sri Lankan women aged 50-69 ${ }^{1}$ living in NSW having a breast screen - 3\% more than the target objective, or $62.5 \%$ ahead of target (see Figure 3);

- An 8\% increase in the number of Indian and Sri Lankan women aged 50-69 living in NSW having a breast screen for the first time in 2014-2015;

- A 10\% increase in the number of Tamil women aged 50-69 living in NSW having a breast screen (5\% more than the target objective, or $100 \%$ ahead of the target);

- A 7\% increase in the number of Hindi women aged 50-69 living in NSW having a breast screen ( $2 \%$ more than the target objective, or $40 \%$ ahead of the target);

- A 48\% increase in the number of Tamil women aged 50-69 living in NSW having a breast screen for the first time in 2014-2015.

Figure 3. Overall increase in Indian and Sri Lankan women aged 50-69 having a breast screen (Source: Cancer Institute NSW, 2015).

Number of screens for all women aged 50-69 who speak one of the

available Indian/Sri Lankan languages

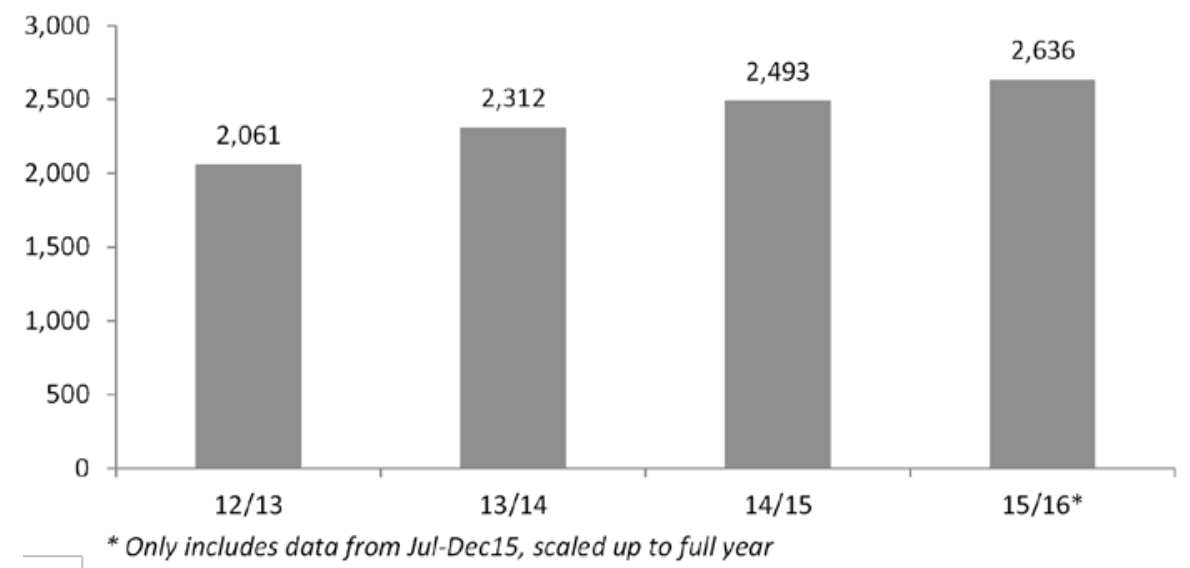


Noting that the effects of the project most likely extended beyond the official end of the project (30 June 2015), it is also relevant to compare breast screening data for the full calendar year 2015 with 2014 - i.e., including the six months immediately following the project. This comparison shows:

- A 6\% increase in the total number of Indian and Sri Lankan women aged 50-69 living in NSW having a breast screen in 2015 compared with 2014;

- A 15\% increase in the number of Indian and Sri Lankan women aged 50-69 living in NSW having a breast screen for the first time in 2015;

- A 10\% increase in the number of Tamil women aged 50-69 living in NSW having a breast screen for the first time in 2015;

- A 21\% increase in the number of Hindi women aged 50-69 living in NSW having a breast screen for the first time in 2015.

No other interventions specifically targeting women from Indian or Sri Lankan backgrounds were conducted during the period of the project so, along with temporal precedence and a relationship between cause and effect (the 'Pink Sari' project during this period), the third criterion of causation has been established - that is, other plausible explanations of the outcomes can be ruled out as far as possible (Trochim, 2006).

In the months following the end of the funded period of the project, there was further anecdotal evidence of the deep engagement by the Indian and Sri Lankan community in the project and its impact. A number of organisations not involved in the original Pink Sari Project asked to become 'partners' in future projects, and Tamil doctors in Sydney requested permission to extend the campaign to promote bowel cancer screening. In reflecting on the project, director of the MCHS, Peter Todaro said: "I've never seen anything more accepted by communities in my career in health promotion” (personal communication, September 1, 2015). Recommendations to improve the cultural competency of breast screening clinics, including additional training of staff and increased access to translators, have been supported by relevant authorities - although implementation is yet to be achieved. In addition, in December 2015 Cancer Institute NSW announced that a further $\$ 100,000$ has been awarded to MHCS to continue the Pink Sari Project in 2016 based on the results achieved.

\section{Discussion and conclusions}

Despite a quite modest budget, the Pink Sari Project conducted by MHCS was demonstrably effective in achieving its primary objective of increasing breast screening rates among women from Indian and Sri Lankan backgrounds. In addition, analysis shows extensive evidence that it achieved its communication objectives to increase awareness and knowledge of the benefits of breast screening within the target audience. The project went some way toward increasing the capacity of screening services to engage effectively with the target communities, but analysis indicates that more work needs to be done to increase cultural competency among service providers.

In addition, beyond results related to the project's specific objectives, this project informs health communication theory and practice and serves as a model for health communication campaigns and interventions in at least three respects.

First, it demonstrates the fundamental importance of a research-led approach. Specifically, it illustrates the vital information provided by in-depth qualitative formative research using a range of methods including literature review, interviews, focus groups, and surveys among target audiences and stakeholders. This is a first step in addressing RQ1. It also demonstrates 
outcome and impact level evaluation and the benefits that this can bring such as providing 'hard' evidence to meet reporting requirements and secure future funding.

Second, the 'Pink Sari' project illustrates the effectiveness of community engagement and participation deployed using a culture-centred approach (CDA). It also operationalised research findings that show the most trusted sources of information and primary influences after family are "people I know" such as peers and friends (Edelman, 2015; Nielsen, 2015, p. 4). This project engaged and galvanised these key influencers rather than deploying expensive top-down mass media campaigns, providing further insights in relation to RQ1. This led to the third key contribution of this case study that substantially addresses RQ2.

The 'Pink Sari' project demonstrates the cost-efficiency and resulting scalability of projects based on community collaboration and participation. Along with the free endorsements of peers and friends, the contribution of volunteer labour and donations of materials and resources such as pink saris and photography enabled a substantial and successful campaign to be created on a 'shoe string' compared with traditional mass media campaigns. Thus, this approach potentially can be implemented by many communities and organisations to achieve scale, which will increase social inclusion and equity.

\section{References}

Atkin, C., \& Silk. K. (2009). Health communication. In D. Stacks \& M. Salwen (Eds.), An integrated approach to communication theory and research (2nd ed., pp. 489-503). New York, NY: Routledge.

Australian Bureau of Statistics. (2013). Migration, Australia, 2011-12 and 2012-13. Canberra, ACT: Author. Retrieved from http://www.abs.gov.au/ausstats/abs@.nsf/Lookup/3412.0Chapter1201112\%20and\%202012-13

Australian Government. (2016). Health promotion. Retrieved from http://www.australia.gov.au/information-and-services/health/health-promotion

Bauman, A., \& Nutbeam, D. (2014). Evaluation in a nutshell: A practical guide to the evaluation of health promotion programs (2nd ed.). North Ryde, NSW: McGraw-Hill.

Bernhardt, J. (2004). Communication at the core of public health. [Editorial]. American Journal of Public Health, 94(12), 2051-2053. Retrieved from http://www.ncbi.nlm.nih.gov/pmc/articles/PMC1448586

Bottorff, J., Johnson, J., Bhagat, R., Grewal, S., Balneaves, L., Clarke, H., \& Hilton, B. (1998). Beliefs related to breast health practices: The perceptions of South Asian women living in Canada. Social Science \& Medicine, 47(12), 2075-2085. doi.org/10.1016/S0277-9536(98)00346-3

Bryant, J., \& Oliver. M. (2009). Media effects: Advances in theory and research (3rd ed.). New York, NY: Routledge.

Cancer Institute NSW. (2014). Evidence to practice grants: Expression of interest brief. Sydney, NSW: Author.

Cancer Institute NSW. (2015, December). Breast screening rates collected from BreastScreen NSW. Sydney, NSW: Author.

CDC (Center for Disease Control and Prevention). (2011). Healthy people 2020. Retrieved from http://www.cdc.gov/nchs/healthy_people/hp2020.htm

Corcoran, N. (2007). Communicating health: Strategies for health promotion. London, UK: Sage.

Creswell, J. (2009). Research design: Qualitative, quantitative and mixed methods approaches (3rd ed.). Thousand Oaks, CA: Sage.

Department of Health and Human Services. (2000). Healthy people 2010 (2nd ed.). Washington, DC: Author.

Dutta, M. (2008). Communicating health: A culture-centered approach. London, UK: Polity.

Dutta, M. (2012). Hunger as health: Culture-centered interrogations of alternative rationalities of health. Communication Monographs, 79, 366-384. doi.org/10.1080/03637751.2012.697632 
Dutta, M., Anaele, A., \& Jones, C. (2013). Voices of hunger: Addressing health disparities through the culture-centered approach. Journal of Communication, 63(1), 159-180. doi:10.1111/jcom.12009

Dutta, M., \& de Souza, R. (2008). The past, present, and future of health development campaigns: Reflexivity and the critical-cultural approach. Health Communication, 23(4), 326-339. doi: 10.1080/10410230802229704

Edelman. (2015). Edelman Trust Barometer. New York, NY: Author. Retrieved from http://www.edelman.com/insights/intellectual-property/2015-edelman-trust-barometer/trustaround-world

European Commission. (2015). Toolkit for the evaluation of communication activities. Brussels, Belgium: Author. Retrieved from http://ec.europa.eu/dgs/communication/about/evaluation/documents/communication-evaluationtoolkit_en.pdf

Finlay, L., \& Gough, B. (2003). Reflexivity: A practical guide for researchers in health and social sciences. Oxford, UK: Blackwell.

Geertz, C. (1973). Thick description: Toward an interpretive theory of culture. In The interpretation of cultures: Selected essays (pp. 3-30). New York, NY: Basic Books.

Harvard. (2016). The field of health communication. Boston, MA: Harvard University School of Public Health. Retrieved from http://www.hsph.harvard.edu/health-communication

Hastings, G., \& Stead, M. (2006). Social marketing. In W. Macdowall, C. Bonell, \& M. Davies (Eds), Health promotion Practice (pp. 139-151). Berkshire, UK: Open University Press.

Hornik, R. (Ed.). (2002). Public health communication: Evidence for behavior change. Mahwah, NJ: Lawrence Erlbaum.

Johansson, R. (2003, September). Case study methodology. Paper presented to the 'Methodologies in Housing Research' international conference of the Royal Institute of Technology in cooperation with the International Association of People-Environment Studies, Stockholm. Retrieved from http://www.psyking.net/htmlobj-3839/case_study_methodology-_rolf_johansson_ver_2.pdf

Johnson, J., Botoroff, J., Balneaves, L., Grewal, S., Bhagat, R., Hilton, B., \& Clarke, H. (1999). South Asian women's views on the causes of breast cancer: Images and explanations. Patient Education and Counselling, 37(3), 243-254.

Karbani, G., Lim, J., Hewison, J., Atkin, K., Horgan, K., Lansdown, M., \& Chu, C. (2011). Culture, attitude and knowledge about breast cancer and preventive measures: A qualitative study of South Asian breast cancer patients in the UK. Asia Pacific Journal of Cancer Prevention, 12(6), 16191626.

Kotler, P., \& Zaltman, G. (1971). Social marketing: An approach to planned social change. Journal of Marketing, 35(3), 3-12. doi.org/10.2307/1249783

Kreps, G. (2014). History of health communication. In T. Thompson (Ed.), Encyclopedia of health communication (pp. 567-572). Thousand Oaks, CA: Sage.

Kreps, G., Bonaguro, E., \& Query, J. (1998). The history and development of the field of health communication. In L. Jackson \& B. Duffy (Eds.), Health communication research: Guide to developments and directions (pp. 1-15). Westport, CT: Greenwood Press.

Kreps, G., \& Thornton, B. (1988). Health communication: Theory and practice. Long Grove, IL: Waveland Press.

MacFadyen, L., Stead, M., \& Hastings, G. (1999). A synopsis of social marketing. Retrieved from http://www.stir.ac.uk/media/schools/management/documents/social_marketing.pdf

MacFadyen, L., Stead, M., \& Hastings G. (2003). Social marketing. In M. Baker (Ed.), The marketing book (5th ed., pp. 694-725). Oxford, UK: Butterworth Heinemann.

Macnamara, J. (2015). Breaking the measurement and evaluation deadlock: A new approach and model. Journal of Communication Management, 19(4), 371-387. doi.org/10.1108/JCOM-042014-0020

Macnamara, J. Dunston, R., \& Monden, M. (2014). Improving breast screening rates for Indian and Sri Lankan women in NSW: What research tell us'. Research report for the NSW Multicultural Health Communication Service, NSW Ministry of Health. Sydney, NSW: University of Technology Sydney.

Maréchal, G. (2010) Autoethnography. In A. Mills, G. Durepos, \& E. Wiebe (Eds.) Encyclopedia of case study research (vol. 2, pp. 43-45). Thousand Oaks, CA: Sage. 
McDonald, B., \& Steel, Z. (1997). Immigrants and mental health. An epidemiological analysis. Sydney, NSW: Transcultural Mental Health Centre.

Meneses, K., \& Yarbro, C. (2007). Cultural perspectives of international breast health and breast cancer education. Journal of Nursing Scholarship, 39(2), 105-112. doi: 10.1111/j.15475069.2007.00154.x

Miles, M., \& Huberman, M. (1994). Qualitative data analysis. Thousand Oaks, CA: Sage.

Minas, I., Lambert, T., Kostov, S., \& Boranga, G. (1996). Mental health services for NESB immigrants. Canberra, ACT: Australian Government Printing Service.

NHMRC (National Health and Medical Research Council). (2005). Cultural competency in health: A guide for policy partnerships and participation. Canberra, ACT: Commonwealth of Australia. Retrieved from http://www.nhmrc.gov.au/_files_nhmrc/publications/attachments/hp19.pdf

Nielsen. (2015, September). Global trust in advertising: Winning strategies for an evolving landscape. New York, NY: Author. Retrieved from

http://www.nielsen.com/content/dam/nielsenglobal/apac/docs/reports/2015/nielsen-global-trust-inadvertising-report-september-2015.pdf

Noble, G., \& Camit, M. (2005). Social marketing communication in a multicultural environment: Practical issues and theoretical contributions from cross-cultural marketing. PRism, 3 (2), 1-13.

Northouse, P., \& Northouse, L. (1985). Health communication: A handbook for health professionals. Englewood Cliffs, NJ: Prentice Hall.

NSW Ministry of Health. (2012). Policy and Implementation Plan for Healthy Culturally Diverse Communities 2012-2016. Sydney, NSW: NSW Government.

Nutbeam, D. (1998). Evaluating health promotion: Progress, problems and solutions. Health Promotion International, 13(1), 27-44.

Panter-Brick, C., Clarke, S., Lomas, H., Pinder, M., \& Lindsay, S. (2006). Culturally compelling strategies for behaviour changes: A social ecology model and case study in malaria prevention. Social Science \& Medicine, 62, 2810-2825. doi: 10.1016/j.socscimed.2005.10.009

Parrott, R. (2004). Emphasizing 'communication' in health communication. Journal of Communication, 54(4), 751-787 doi: 10.1111/j.1460-2466.2004.tb02653.x

Pelissier, F., Garbe, J., Anathanarayanan, B., Mivano, M., Lin, C., Jokela, T., ... LaBarge, M. (2014). Age-related dysfunction in mechanotransduction impairs differentiation of human mammary epithelial progenitors. Cell Reports, 7(6), 1926-1939. doi.org/10.1016/j.celrep.2014.05.021. Retrieved from http://www.cell.com/cell-reports/abstract/S2211-1247(14)00396-9

Rao, D., Warburton, J., \& Bartlett, H. (2006). Health and social needs of older Australians from culturally and linguistically diverse backgrounds: issues and implications, Australasian Journal of Ageing, 25(4), 174-179. doi: 10.1111/j.1741-6612.2006.00181.x

Renzaho, A., Romios, P., Crock, A., \& Sønderlund, A. (2013). The effectiveness of cultural competence programs in ethnic minority patient-centred health care: A systematic review of the literature. International Journal for Quality in Health Care, 25(3), 261-269.

Rice, R., \& Atkin, C. (2002). Communication campaigns: Theory, design, implementation, and evaluation. In J. Bryant \& D. Zillman (Eds.), Media effects: Advances in theory and research (2nd ed., pp. 427-451). Mahwah, NJ: Lawrence Erlbaum.

Rossi, P., Freeman, H., \& Lipsey, M. (2004). Evaluation. A systematic approach (7th ed.). Thousand Oaks, CA: Sage.

Rossiter, J., \& Bellman, S. (2005). Marketing communications: Theory and applications. New York, NY: Prentice Hall.

Saadi, A., Bond, B., \& Percac-Lima, S. (2012). Perspectives on preventive health care and barriers to breast cancer screening among Iraqi women refugees. Journal of Immigrant Minority Health, 14(4), 633-639. doi: 10.1007/s10903-011-9520-3.

Sawrikar, P., \& Katz, I. (2009). How useful is the term 'culturally and linguistically diverse' (CALD) in Australian research and policy discourse? Sydney, NSW: Social Policy Research Centre, University of New South Wales. Retrieved from http://apo.org.au/research/how-useful-termculturally-and-linguistically-diiverse-cald-australian-research-and-policy

Schramm, W. (1971). Notes on case studies for instructional media projects. Working paper for Academy of Educational Development, Washington DC. Retrieved from http://files.eric.ed.gov/fulltext/ED092145.pdf

Shiavo, R. (2014). Planning, implementing, and evaluating a health communication intervention. In Health communication: From theory to practice ( $2^{\text {nd }}$ ed., Part 3). San Francisco, CA: Jossey-Bass. 
Slade, D., Manidis, M., McGregor, J., Scheeres, H., Chandler, E., Stein-Parbury, J., ... Matthiessen, C. (2015). Communicating in hospital emergency departments. New York, NY: Springer.

Stake, R. (1995). The art of case study research. Thousand Oaks, CA: Sage.

Stead, M., \& Hastings, G. (1997). Advertising in the social marketing mix: Getting the balance right. In M. Goldberg, M. Fishbein, \& S. Middlestadt (Eds.), Social marketing: Theoretical and practical perspectives (pp. 29-44). Mahwah, NJ: Lawrence Erlbaum.

Tanaka, A., Gaye, L., \& Richardson, R. (2010). Co-production and co-creation: Creative practice in social inclusion. In R. Nakatsu, N. Tosa, F. Naghdy, K. Wong, \& P. Codognet (Eds.), Cultural computing (pp. 169-178). Berlin, Heidelberg, Germany, Springer.

Tedlock, B. (2008). The observation of participation and the emergence of public ethnography. In N. Denzin \& Y. Lincoln (Eds.) Strategies of qualitative inquiry (3rd ed., pp. 151-171). Thousand Oaks, CA: Sage.

Trochim, W. (2006). Establishing cause and effect. Research Methods Knowledge Base. Retrieved from http://www.socialresearchmethods.net/kb/causeeff.php

Valente, T. (2001). Evaluating communication campaigns. In R. Rice \& C. Atkin (Eds.), Public communication campaigns (3rd ed., pp. 105-124). Thousand Oaks, CA: Sage.

Wholey J., Hatry, H., \& Newcomer, K. (Eds.). (2010). Handbook of practical program evaluation (3rd ed.). San Francisco, CA: Jossey-Bass.

Watson, T., \& Noble, P. (2014). Evaluating public relations: A best practice guide to public relations planning, research and evaluation ( $3^{\text {rd }}$ ed.). London, UK: Kogan Page.

WHO (World Health Organisation). (2005). The Bangkok charter for health promotion in a globalised world. Proceedings of the 6th Global Conference on Health Promotion, Bangkok. Retrieved from http://www.who.int/healthpromotion/conferences/6gchp/hpr_050829_\%20BCHP.pdf

Yin, R. (2009). Case study research: Design and methods (4th ed.). Thousand Oaks, CA: Sage.

\section{Published reference:}

Macnamara J., \& Camit, M. (2016, in print). Effective CALD community health communication through research and collaboration: An exemplar case study. Communication Research \& Practice. doi.org/10.1080/22041451.2016.1209277

Jim Macnamara PhD is Professor of Public Communication at the University of Technology Sydney, a position he took up in 2007 after a 30-year professional career spanning journalism, public relations and media research. He is the author of 15 books including The $21^{\text {st }}$ Century Media (R)evolution: Emergent Communication Practices (Peter Lang, New York, 2014) and Organizational Listening: The Missing Essential in Public Communication (Peter Lang, New York, 2016).

Michael Camit is Manager, Communication and Social Marketing at the Multicultural Health Communication Service, a specialist unit of NSW and a PhD student at the University of Technology Sydney. He holds a Master of Marketing (Research) in social marketing from the University of Wollongong and a Master of Education in applied linguistics (TESOL) from the University of Sydney.

1 Until 2014, Cancer Institute NSW collected breast screening data only for 50-69 year olds, not for 70-74 year olds. Therefore this age range was used to allow comparison with previous years. 